\title{
Marine mammal research: its relationship to other scientific disciplines and to wider society
}

\author{
PETER G.H. EVANS ${ }^{1,2}$, PIA ANDERWALD ${ }^{3}$ AND ANDREW J. WRIGHT ${ }^{4}$ \\ ${ }^{1}$ Sea Watch Foundation, Ewyn y Don, Bull Bay, Amlwch, Anglesey, LL68 9SD, UK, ${ }^{2}$ School of Ocean Sciences, University of Bangor, \\ Menai Bridge, Anglesey LL59 5AB, UK, ${ }^{3}$ Swiss National Park, Chastè Planta-Wildenberg, 7530 Zernez, Switzerland, ${ }^{4}$ Department of \\ Environmental Science \& Policy, George Mason University, 4400 University Drive, Fairfax, VA 22030, USA
}

Submitted 20 May 2014; accepted 20 May 2014

Marine mammals occupy a special place both within the marine ecosystem as top predators, and within society as an iconic animal group that captures the attention and hearts of the general public. The lives of marine mammals and humans have long been closely entwined. For some thousands of years, humans have depended upon them for food, clothing, cosmetics and even heating and lighting. At the same time they have been viewed with wonder, and myths have developed around them, ranging from tales of mermaids and unicorns to leviathans-mysterious monsters of the deep. Beyond cave paintings and rock carvings, the earliest writings on animal life that have been preserved to us are those of the Greek philosopher Aristotle who lived from 384 to $322 \mathrm{BC}$, and wrote numerous descriptions of animals he had studied and dissected. Whereas many others after him have viewed cetaceans as sea-fish, Aristotle's accounts show that he understood cetaceans to be distinct from fish, noting that they possessed lungs and a blowhole instead of gills to breathe air, and that they also bore live young (see Aristotle's On the Parts of Animals and Historia Animalium). He considered them intermediate between land animals and the truly aquatic animals such as fish. It is remarkable that even now in the 21 st Century, there are people in this world that still think of them as fish.

Probably the most famous reference to a whale is the allegorical story of Jonah in the Bible-how he was cast into the sea by sailors to calm the raging storm, then swallowed by a whale (referred to as a 'great fish'), and after three days vomited up onto dry land. Artists down the centuries have illustrated this in paintings, as they have another biblical beast that is thought to be a whale-'Leviathan', although descriptions include teeth and scales, and a body like a huge serpent.

Corresponding author:

P.G.H. Evans

Email: peter.evans@bangor.ac.uk
Many of the features of marine mammals that have been subject to scientific enquiry, particularly in the last 50-100 years, have been touched on earlier in literature, folklore and mythology, even if at times somewhat embellished. Dolphins coming to the aid of other dolphins in distress; the legend of Arion rescued by a dolphin and carried to safety on its back; breaching, behaviours such as bow-riding, food herding and capture, and predator defence; gestation periods, timing of calving, care for the young, social relationships, and dolphins associating with humans-all these are described in one form or another. The larger whales were generally feared-represented as monsters that can sink a vessel if they so wished. In later centuries, however, the products of whales were utilized in many different ways-whalebones serving both as ornaments and practical artefacts-arches, gateposts, fencing, gravestones, mooring bollards, crane hoists and roof supports, to name but a few (Barthelmess, 2003; Redman, 2004, 2009). Entire coastal towns and cities have been built upon the trade in cetaceans and seals, alongside other marine organisms like fish.

We, as a species, still hunt marine mammals in our quest for meat and various other commodities. However, with some notable exceptions, the industrialized hunting of the past, which caused major population declines and even extinctions of some marine mammals (notably the Atlantic gray whale, Steller's sea cow and the Caribbean monk seal), has given way to whale watching and ecotourism. Nowadays, we recognize their intelligence, apparent friendliness and curiosity towards humans, incorporating these traits into modern literature, music, film and theatre. We observe them in awe, seeking pleasure in encounters with them above and below the surface of their aquatic world, in the wild and in captivity, with some people even using them in attempts to cure people of depressive illness. Thus we see marine mammals throughout history serving a continually changing, but consistently important role in all aspects of human society.

In contrast to the way that marine mammals have infiltrated many aspects of society, the study of marine mammals has 
taken a long time to be embraced by other biological disciplines. Within marine sciences, it remains the case that many oceanographic institutes focus upon the lower trophic levels from fish down, and are only peripherally involved in studying top predators such as marine birds and mammals. Recent attempts to integrate these different marine science disciplines have been more successful with seabirds than with marine mammals, although increasing attention is being paid to the latter, perhaps more so in North America than in Europe.

The European Cetacean Society held two recent conferences aimed at reaching out beyond consideration of marine mammal science in isolation. Its 26th Annual Conference was held in Galway, Ireland on 26-28 March 2012 and addressed the theme of 'Information and Ideas Worth Sharing', whilst the 27th Annual Conference held in Setúbal, Portugal on 8-10 April 2013 was on the theme of 'Interdisciplinary Approaches in the Study of Marine Mammals'.

The location of Galway for the conference in 2012 was particularly fitting, given the strong cultural heritage for music and literature in the region. This was exemplified by the weaving of music and the arts into the scientific programme at the conference, in the manner of the rich tradition established by the annual Conamara Sea Week that, for a quarter of a century, has mixed together science, music and the arts in celebration of the sea.

An important reason why the study of live marine mammals at sea has only recently received more focused attention is probably their high mobility and often very large home ranges, which make it logistically and financially difficult to follow individuals or groups for long enough to obtain meaningful scientific results. However, the spatial scales over which marine mammals range make them particularly interesting study subjects for the application of ecological theories that were often developed under far more local, controlled conditions.

Despite the apparent lack of physical boundaries in the marine environment, geographical differences, often at surprisingly fine spatial scales, are reflected in the morphology, phenology, behavioural ecology, diet and ultimately population genetic structure of the various marine mammals that were once thought to freely roam the oceans. Thus, Arcoverde et al. (2014) found consistent morphological differences in the middle ear of Sotalia guianensis between the coasts of northern and south-eastern Brazil, consistent with population genetic structure.

The importance of considering regional differences in research when extrapolating from the literature is illustrated by Garibaldi \& Podestà (2014), who derived an area-specific beak size-cephalopod size regression for Histioteuthis bonnelli, the dominant prey species found in the stomach of a stranded male sperm whale, Physeter macrocephalus, in Italy. Their reconstructed prey weight for the species in the Ligurian Sea was higher than estimates from the literature, highlighting a need for species- and area-specific regressions for dietary studies. Similarly, Cronin et al. (2014) found that the timing of the moulting period of harbour seals, Phoca vitulina, in south-west Ireland differed from that in other parts of the species' range. This may have implications on the optimal timing of abundance surveys in the region, as harbour seal counts are mainly conducted during the moulting season.
The flexibility of a species in adapting to different ecological circumstances in space and time is illustrated by both cetaceans and pinnipeds. The diet of the poorly known Shepherd's beaked whale, Tasmacetus shepherdi, which differs in its dentition from most other mainly teuthophagous beaked whales, seems to consist of both cephalopods and fish, depending on time of day and physical habitat characteristics. These findings are based on the stomach contents of an adult female stranded on Tristan da Cunha (Best et al., 2014).

Using scats and stable isotope analysis, Páez-Rosas \& Aurioles-Gamboa (2014) found that despite stability in trophic level, the diet of Galapagos sea lions, Zalophus californianus wollebaeki, was variable in space and time, which likely helps the species survive in an ecosystem with limited and fluctuating resources.

In the North Atlantic, northern bottlenose whales, Hyperoodon ampullatus, are thought to undergo seasonal latitudinal migrations, northwards towards polar regions in spring and southwards to warm temperate regions in autumn. A study of the stomach contents of ten animals that stranded in UK, Ireland and The Netherlands between August and October, revealed a wide diversity of cephalopod species (21 species from 16 families), including three warm temperate cephalopod species in three bottlenose whale stomachs (Fernández et al., 2014). Those results suggest that some animals at least may have entered the region from the south.

At regional scales, monitoring efforts can sometimes yield surprising findings even on well-studied species, which may deviate from generally accepted patterns, for example on mysticete migration. Passive acoustic monitoring of Massachusetts Bay over a two-year period by Murray et al. (2014) showed that humpback whales, Megaptera novaeangliae, do not seem to use the area only as a feeding ground during spring and summer, but are present year-round, though with maximum presence from spring to early winter and minimum presence during mid-winter.

Inter-specific interactions were the subject of the study by Degrati et al. (2014) who investigated associations between seabirds of various species and dusky dolphins Lagenorhynchus obscurus, in Golfo Nuevo, Argentina. Certain species of seabirds, such as Magellanic penguins, Spheniscus magellanicus, were not found to associate with dolphins at all, while others, like shearwaters, were mainly observed in association with dolphins, but mostly when the dolphins were engaged in surface feeding. Degrati et al. (2014) suggest that the birds may be utilizing the dolphins as a foraging strategy, but find no benefit to the dolphins in the interactions.

Maintaining animal health in captive populations of marine mammals is both a welfare concern and a basic requirement for studies in which they are involved, especially those of a behavioural nature. Anzolin et al. (2014) advocate increased enrichment of enclosures for manatees (Trichechus spp.) in reintroduction oceanaria, based on their findings of the prevalence of stereotypic behaviours at three such facilities in north-eastern Brazil.

Manatees were also the study animals for Kikuchi et al. (2014), who recorded feeding sounds, such as mastication, using animal-borne acoustic recording systems. Although mastication cycles varied by individual and food species, custom-built automatic detection scripts correctly identified $79 \%$ of feeding events, with only a $7.3 \%$ false alarm rate, and revealed that manatees are less active and masticate slower at night, despite foraging at all times. 
With more direct conservation implications, Gonzalvo et al. (2014) used photo-identification (photo-ID) to assess the population of common bottlenose dolphin, Tursiops truncatus, in coastal waters of the Balearic Islands, and found that they display strong site-fidelity and limited mobility across the archipelago. The population was also found to be relatively small, despite the fact that the area has long been considered a regional hot spot for the species, and the authors called for additional conservation measures due to the large and increasing anthropogenic pressures in the area, especially from mass tourism.

Pollution remains a major component of European marine ecosystems, particularly in the coastal zone. Lauriano et al. (2014) examined organochlorine concentrations in both free-living and stranded cetaceans in the Mediterranean and also morbillivirus and Toxoplasma gondii infections in stranded specimens. Extremely high concentrations of polychlorinated biphenyls (PCBs) and dichlorodiphenyltrichloroethane (DDT) were recorded in the blubber of free-ranging long-finned pilot whales, Globicephala melas, and tissues of stranded bottlenose dolphins and striped dolphins, Stenella coeruleoalba. PCB concentrations in the two latter species were above levels expected to have adverse effects in marine mammals. The authors suggest that associated immunosuppression may have contributed to the Toxoplasma gondii infection found in three of 15 stranded striped dolphins and six of nine stranded bottlenose dolphins.

Sometimes threats to cetaceans can also have direct implications for humans. Anisakid parasite loads in ringed seal, Pusa hispida, and the bearded seal, Erignathus barbatus, were investigated by Karpiej et al. (2014) with respect to the risks these parasites may present to Canadian indigenous communities, which consume these seals and also various Arctic fish species that act as intermediate hosts. Seals hunted by two Nunavut communities were found to have 2428 and 316 anisakids (in 37 seals from Arviat and 29 seals from Sanikiluaq). The most numerous nematodes were Pseudoterranova bulbosa, and mixed infection was observed. While the advanced life stages of anisakid parasites in the seals suggests low risk to humans, the pinnipeds may still act as a vector for the more invasive younger stages present in many fish species.

In some parts of the world, marine mammals are perceived rightly or wrongly as a threat, competing with fisheries for local resources. Along the Israeli coastline, common bottlenose dolphins and bottom trawlers exploit the same ecological niche, each estimated to take annually a very similar quantity of fish. Using stomach contents and stable isotope analysis, Scheinin et al. (2014) examined whether the two indeed do compete for the same resource. They found some similarity (a Pianka index of 0.49 , as a measure of the overall similarity of the composition of the pooled biomass and that of the average commercial catch), with sea bream (Sparidae) being the main family important to both.

With the increasing pressures placed on the marine environment with rising human populations and per capita consumption, much marine science has focused upon research and monitoring to improve the conservation of biodiversity. A number of papers in this issue contribute to that objective. Stringell et al. (2014), faced with the challenge of measuring Welsh Atlantic grey seal, Halichoerus grypus, pup production in cryptic breeding habitats such as caves (which cannot easily be monitored by conventional aerial surveys), compare a ground-based pup production census with a reduced effort plotsampling survey to estimate pup production, derive a total population size, and assess cost-effectiveness. The plot-sampling design resulted in a very similar overall estimate of pup production (91 vs 96) whilst reducing survey effort by $46 \%$ and saving $30 \%$ on logistical costs compared to the full census.

While all efforts to identify and conserve biodiversity face logistical challenges, constraints on resources for surveys and research are likely to be greatest in the developing world. Rising to that challenge, Luksenburg (2014) presents the results of cetacean strandings and boat-based surveys of the coastal waters around the island of Aruba in the Caribbean in 2010 and 2011. Eight cetacean species were observed, bringing the total number of species recorded in Aruban waters to sixteen. Atlantic spotted dolphin, Stenella frontalis, and bottlenose dolphin, were the most frequently observed species, with sightings of both year-round, followed by spinner dolphin, S. longirostris, and false killer whale, Pseudorca crassidens. Additional species included pantropical spotted dolphin, S. attenuata, striped dolphin, S. coeruleoalba, long-beaked common dolphin, Delphinus capensis, roughtoothed dolphin, Steno bredanensis, short-finned pilot whale Globicephala macrorhynchus, killer whale, Orcinus orca, Risso's dolphin, Grampus griseus, humpback whale, Bryde's/ Eden's whale, Balaenoptera brydei/edeni, sperm whale, and an unidentified beaked whale, Mesoplodon sp.

In order to monitor trends in population size, estimates of abundance are required. Bottlenose dolphins, which often have unique marking patterns in the form of nicks in their dorsal fin, lend themselves to photo-ID of individuals and estimates of population size derived from mark-recapture analysis. Using photo-ID data gathered over an eleven-year period, Pulcini et al. (2014) present the first such estimates for the bottlenose dolphin population inhabiting the waters around Lampedusa Island, Italy, finding that the population had increased between 1998 and 2006, with evidence of longterm site fidelity.

For species that frequently occupy coastal waters, shorebased systematic watches can yield valuable information. Dolman et al. (2014) collected data from such watches over 47 days during spring and autumn periods from October 2008 to April 2011, in order to assess the seasonal occurrence, group size and group behaviours of cetaceans in a study area located off Melvaig, near Gairloch, north-west Scotland. Over that period, they had 126 cetacean sightings, 50 seal sightings, and 13 sightings of basking sharks, Cetorhinus maximus. Six species of cetacean were identified, with most sightings comprising harbour porpoise, Phocoena phocoena, or minke whale, Balaenoptera acutorostrata. Harbour porpoise abundance was higher in autumn than in spring, and there was a variation between years in numbers of minke whales sighted. The authors suggest that given the regular occurrence of both species in reasonable numbers in the area and the occurrence of a range of human activities potentially affecting them in the region, it may be appropriate to consider protecting this area for their conservation.

Acoustics is another method frequently used to monitor the occurrence of cetaceans. Static acoustic monitoring has the advantage of being able to provide detailed information on species presence at different temporal scales-revealing $24 \mathrm{~h}$, seasonal and annual variation. Dede et al. (2014) 
deployed a fixed stereo passive acoustic monitoring system (A-tag) in the middle of the Istanbul Strait between July 2009 and September 2010, to monitor the clicks of three cetacean species-harbour porpoise, short-beaked common dolphin, and bottlenose dolphin inhabiting the Strait. Most click trains were detected during the night-time although during March and April, a diel pattern of presence was observed. At that time, the cetaceans were concentrated in one specific direction from the fixed monitoring system. In contrast, they were found in all directions for the rest of the year. The presence of short-range sonar (inter-click intervals) suggested that they were feeding or socializing in spring but mostly travelling in the other seasons. It is well known that pelagic fish such as sprat and bluefish start their migration from the Aegean Sea to the Black Sea in spring. This study suggests that the cetaceans use the middle part of the Strait for feeding on the pelagic fish in spring when the fish migration has just started.

Human society largely now views marine mammals not as a resource to exploit, but as a group of mammals to admire, respect and enjoy-a group that is especially vulnerable to a range of anthropogenic pressures which never lessen as the years go by. There are benefits to this special status for improving our understanding and conservation of marine ecosystems in general. As a consequence, marine mammal research should be better incorporated in wider marine biological studies. Indeed, not just marine mammals, but all marine organisms should receive greater attention in ecological and behavioural journals that are still dominated by publications of studies drawn only from the terrestrial environment. Each has much to learn from the other, and this crossfertilization should be encouraged wherever possible.

\section{REFERENCES}

Anzolin D.G., De Carvalho P.S.M., Viana P.C. Jr, Normande I.C. and Souto A.d.S. (2014) Stereotypical behaviour in captive West Indian manatee (Trichechus manatus). Journal of the Marine Biological Association of the United Kingdom 94, 1133-1137.

Arcoverde D.L., Emin-Lima R., Costa A.F., Di Beneditto A.P.M., Siciliano S., Sena L., Moreno I.B. and De Sousa E.J. Jr (2014) Evaluation of periotic-timpanic bone complex of Sotalia guianensis (Cetacea: Delphinidae) as tool in identification of geographical variations. Journal of the Marine Biological Association of the United Kingdom 94, 1127-1132.

Barthelmess K. (2003) Whale strandings in the culture and economy of medieval and early modern Europe. Isana 27, 5-10.

Best P.B., Smale M.J., Glass J., Herian K. and von der Heyden S. (2014) Identification of stomach contents from a Shepherd's beaked whale Tasmacetus shepherdi stranded on Tristan da Cunha, South Atlantic. Journal of the Marine Biological Association of the United Kingdom $94,1093-1097$.

Cronin M., Gregory S. and Rogan E. (2014) Moulting phenology of the harbour seal in south-west Ireland. Journal of the Marine Biological Association of the United Kingdom 94, 1079-1086.

Dede A., Öztürk A.A., Akamatsu T., Tonay A.M. and Öztürk B. (2014) Long-term passive acoustic monitoring revealed seasonal and diel patterns of cetacean presence in the Istanbul Strait. Journal of the Marine Biological Association of the United Kingdom 94, 1195-1202.

Degrati M., Dans S.L., Garaffo G.V. and Crespo E.A. (2014) Seabird and dolphin association: do seabirds benefit from feeding in association with dusky dolphins in Patagonia? Journal of the Marine Biological Association of the United Kingdom 94, 1147-1153.

Dolman S.J., Hodgins N.K., MacLeod C.D., Pierce G.J. and Weir C.R. (2014) Harbour porpoises (Phocoena phocoena) and minke whales (Balaenoptera acutorostrata) observed during land-based surveys in The Minch, north-west Scotland. Journal of the Marine Biological Association of the United Kingdom 94, 1185-1194.

Fernández R., Pierce G.J., Macleod C.D., Brownlow A., Reid R.J., Rogan E., Addink M., Deaville R., Jepson P.D. and Santos M.B. (2014) Strandings of northern bottlenose whales, Hyperoodon ampullatus, in the north-east Atlantic: seasonality and diet. Journal of the Marine Biological Association of the United Kingdom 94, 1109-1116.

Garibaldi F. and Podestà M. (2014) Stomach contents of a sperm whale (Physeter macrocephalus) stranded in Italy (Ligurian Sea, northwestern Mediterranean). Journal of the Marine Biological Association of the United Kingdom 94, 1087-1091.

Gonzalvo J., Forcada J., Grau E. and Aguilar A. (2014) Strong sitefidelity increases vulnerability of common bottlenose dolphins Tursiops truncatus in a mass tourism destination in the western Mediterranean Sea. Journal of the Marine Biological Association of the United Kingdom 94, 1227-1235.

Karpiej K., Simard M., Pufall E. and Rokicki J. (2014) Anisakids (Nematoda: Anisakidae) from ringed seal, Pusa hispida, and bearded seal, Erignathus barbatus (Mammalia: Pinnipedia) from Nunavut region. Journal of the Marine Biological Association of the United Kingdom 94, 1237-1241.

Kikuchi M., Akamatsu T., Gonzalez-Socoloske D., De Sousa D.A. Olivera Gomez L.D. and Da Silva V.M.F. (2014) Detection of manatee feeding events by animal-borne underwater sound recorders. Journal of the Marine Biological Association of the United Kingdom 94 $1139-1146$.

Lauriano G., Di Guardo G., Marsili L., Maltese S. and Fossi M.C. (2014) Biological threats and environmental pollutants, a lethal mixture for Mediterranean cetaceans? Journal of the Marine Biological Association of the United Kingdom 94, 1221-1225.

Luksenburg J.A. (2014) The cetaceans of Aruba, southern Caribbean. Journal of the Marine Biological Association of the United Kingdom 94, $1161-1174$.

Murray A., Rice A.N. and Clark C.W. (2014) Extended seasonal occurrence of humpback whales in Massachusetts Bay. Journal of the Marine Biological Association of the United Kingdom 94, 1117-1125.

Páez-Rosas D. and Aurioles-Gamboa D. (2014) Spatial variation in the foraging behaviour of the Galapagos sea lions (Zalophus wollebaeki) assessed using scat collections and stable isotope analysis. Journal of the Marine Biological Association of the United Kingdom 94, 10991107.

Pulcini M., Pace D.S., La Manna G., Triossi F. and Fortuna C.M. (2014) Distribution and abundance estimates of bottlenose dolphins (Tursiops truncatus) around Lampedusa Island (Sicily Channel, Italy): implications for their management. Journal of the Marine Biological Association of the United Kingdom 94, 1175-1184.

Redman N.B. (2004) Whales' bones of the British Isles. Teddington, UK: Redman Publishing, 417 pp.

Redman N.B. (2009) Decorative and practical uses of the bones of large whales. In Brito C. and Evans P.G.H. (eds) Marine mammal history. European Cetacean Society Special Publication Series No. 50, pp. 33-35.

Scheinin A., Kerem D., Lojen S., Liberzon J. and Spanier E. (2014) Resource partitioning between common bottlenose dolphin (Tursiops truncatus) and Israeli bottom trawl fishery for limited resources? Assessment by stomach contents and tissue stable isotopes analysis. Journal of the Marine Biological Association of the United Kingdom 94, 1203-1220. 
and

Stringell T.B., Millar C.P., Sanderson W.G., Westcott S.M. and McMath M.J. (2014) When aerial surveys will not do: grey seal pup production in cryptic habitats of Wales. Journal of the Marine Biological Association of the United Kingdom 94, 1155-1159.

\section{Correspondence should be addressed to:}

P.G.H. Evans

Sea Watch Foundation Ewyn y Don, Bull Bay, Amlwch Isle of Anglesey LL68 9SD

email: peter.evans@bangor.ac.uk 